\title{
Proposal of a Curriculum Redesign of a Bachelor's Degree Program
}

\author{
Martha Lorena Obermeier Perez, Angel Claver Espinoza Muñoz, Keila Citlalli Palacios Lopez
}

Language School, University of Chiapas, Tapachula, Chiapas, Mexico

Email address:

lorena.obermeier@gmail.com (M. L. O. Perez)

\section{To cite this article:}

Martha Lorena Obermeier Perez, Angel Claver Espinoza Muñoz, Keila Citlalli Palacios Lopez. Proposal of a Curriculum Redesign of a Bachelor's Degree Program. Teacher Education and Curriculum Studies. Vol. 2, No. 6, 2017, pp. 93-100. doi: 10.11648/j.tecs.20170206.13

Received: June 23, 2017; Accepted: August 21, 2017; Published: December 25, 2017

\begin{abstract}
The purpose of this research was to find why students have a low English level and what factors they face when learning English. Furthermore, this research pursued on a proposal of a Curriculum redesign which would serve as an element to increase the level of English and at the same time avoid negative factors that hinder the learning process in English Language Teaching (ELT) students. It was assumed that the issue may originate from the Curriculum because it has been found that that it was not sophisticated enough to placate students' needs.
\end{abstract}

Keywords: Curriculum Design, English Language Teaching, Training English Trainers

\section{Introduction}

In the following research that was carried out at a Mexican southeastern university, some negative factors that hinder the learning process in English Language Teaching students were analyzed with the objective of proposing a Curriculum redesign which will function as an element to increase the level of English in ELT students. There are many different factors that impede the learning of English. Some of the factors that affect the learning of English and their possible solutions will be presented in this research.

It was observed that a noticeable amount of students had a low English level, even though they had been evaluated with exams like PET (Preliminary English Test) and FCE (First Certificate in English) which certify that they have an appropriate English level. It has also been noticed that undergraduates in ninth semester have an intermediate English level, when they should have an advanced level. After observing this throughout a long period of time, it was assumed that the problem may be the way the Curriculum was elaborated.

\section{Literature Review}

\subsection{The Importance of the English Language}

In this day and age, English is a remarkably demanding language; and due to the fact that English is vastly important, it is indispensable to have a proficient level. English is the most common language in the contemporary society, therefore the impact that it has worldwide is of great consequence for several reasons.

A lingua franca is a language system that allows communication between humans that do not share the same native language, and to alleviate such state of affairs in communication, English is used. To learn this prominent language, one may do so in two distinctive manners; acquiring the language by living in an English speaking country, or the most standard approach to learning English is through a school, known as education. Therefore, there is an urgent need for teacher education programs that develop competent professionals with a high proficiency in languages and appropriate content and knowledge [1].

\subsection{Factors That Hinder the Learning Process in ELT Students}

English is important and many people are in the need of learning English. Whether they are learning English for an employment, school, pleasure or whichever may be the cause, the purpose that each individual may have depends on the need they have; this is known as ESP (English for Special/Specific Purposes) which leads to EOP (English for Occupational Purposes).

Therefore, for a person who is interested in something 
that is not in their mother tongue, it is extremely important to understand the message, but when there is a low proficiency level in English, the outcome obtained will not be gratifying. There are many possible reasons to learn English. For some students it is mandatory in their bachelor's degree, some need it to study abroad and some others for occupational reasons [2].

For example, if a Spanish-speaking person wants to know information that is not in their mother tongue, then a translation is carried out. When a translation is done incorrectly, the obtained result will not match the original ideas, and the message will be lost. Due to the lack of English, the translation will have been done in a poor manner, and this implies time loss.

In view of that, to develop the language at a professional level, many people go to bilingual schools or specialized centers in English; with the sole purpose of schema building, or to simply learn English. In addition to this, many scholars look forward to obtaining a certificate demonstrating mastery of this particular language. Probably the greatest number of language students in the world do it because it is on the school curriculum whether they like it or not. For many of these students English, in particular, is something that both they and their parents want to have taught.

Even though it may seem as an effortless task to learn a second language, in this case English, there are quite a few factors that need to be taken into account. The factors may vary according to each student and his/her surroundings. The surroundings will depend on whether they facilitate the learning process of a second language or hinder it.

\subsection{Background Knowledge}

It is of great importance to mention that English is found in private schools and in public schools, but there are some differences. In private schools, English is found in all education levels, from kindergarten to university. On the other hand, since public education is free, English is not looked upon as a serious subject. In public schools, English is not mandatory in elementary as a subject and it starts to play an important role in junior high school, high school, and university as well.

The English language is not linked to the entire educational system as an essential compulsory subject to take (English is only obligatory in junior high school, and in high school). Thus, in most public schools learning this particular foreign language is not stipulated. In view of that, there is a lack of knowledge, culture and the interaction between the target language and the mother tongue is non-existing.

English is only taught in public junior high schools and high schools. In order to have better students prepared in English, this language should be integrated in public elementary schools nationwide as a mandatory subject. Due to the fact that English is not taught with the same results in private and public schools, the English level that students have is not equal, creating inequality in classrooms and in work conditions. It is necessary to improve the language teaching in elementary and high school by hiring more experienced teacher in programs focused on training English teachers. Graduates have language proficiency when their trainers organized their teaching considering their professional interests [3].

When students complete their high school education and project themselves for college, they face a serious problem because English is a subject that is mandatory in many universities, if not all. The objective of taking English in college is to prepare professionals who can perform their skills anywhere in the world without any problem, where the lingua franca is English. However, a lot of students nationwide are facing various coefficients for learning English as a second language. Some of the most noticeable problems that students are facing nowadays in a bachelor degree in a southeastern Mexican university will be presented.

Some factors that affect the students' performance in English are the fear of making a mistake, personality traits as shyness, hesitation and lack of confidence while speaking [4]. An important factor that needs to be deeply analyzed is the personal background of a student; it is perhaps the most important to take into account as the student may have advantages over some other students who may be in the same English course. In an English course, there are going to be students who have a higher level than others, which may result as a negative impact to those who are not as competent.

\subsection{Low and High Level of ELT Students in the Classroom}

As noted, one of the main obstacles to obtain a good level of English is the English level of variability that exists in every student. To begin, it is nearly impossible to find a classroom in which all students have the same level of English. Students with a low-level of English find it hard to keep up with the classroom rhythm. These students struggle with carrying out tasks, and sometimes they slow down the learning process of others. Every student has a personal pace for learning, which is influenced by several factors. For those who have a low achievement, this can be due to variables related to learner-related personality traits (motivation, anxiety) and socio cultural variables (influence of the L1, society, culture) [5].

Furthermore, completing assignments is sometimes too difficult that they seek for help, and hardly do their own work as it is practically done for them. In worst case scenarios, these students sometimes give up. Hence, low-level students are affected in the learning process because their peers learn faster than they do and cause demotivation. On the other hand, there are intermediate students who can keep up with the classroom rhythm and are able to interact with their peers without difficulty. These intermediate students do not struggle with the tasks that they are given. Even though intermediate students are higher than low-level students they seem to be static with their language because they are not obliged to keep on improving, they are satisfied with the language they possess.

Finally, in a classroom with low-level and intermediate students, advanced students are found. Advanced students are 
those who are always challenging themselves. Because advanced students have a higher level than the rest of the class, they may become restless and distract others as they finish with the activities quickly. These advanced students either help their classmates or sometimes affect them in an unconscious way because they are looked upon as threats and overshadow their peers.

\subsection{Curriculum Design}

Given the demand of learning English around the world, the role of the English teacher has increased its importance [6]. The programs to train future English teachers should consider to train them in methodology, as well as in the four skills of language. Non-native English teachers have an advantage over native English teachers: they know already what would be difficult to understand due to the differences between the languages and how to overcome these difficulties.

In order to have students with proficiency in English, it is necessary to offer powerful opportunities to future English trainers [7]. Schools need to have qualified teachers in order to provide good education. Despite having qualified teachers in an institute though, a guideline needs to be followed in order to achieve all the goals these teachers may have. Future teachers are transformatory intellectuals who empower others [8]. A prestigious school achieves its ranking due to its reputation it obtains throughout time for being efficient and proactive.

Throughout the years in education, students have adapted to learning methods which have helped them sustain their knowledge through courses designed for specific purposes in language teaching; but currently both society and young apprentices have changed dramatically. The way of teaching - learning is taught differently than in the past, because as everything evolves, information becomes more accessible than in the past. In present day, the information that is available is astounding, yet, many do not take advantage of this.

Society needs a change that is effective both in general and in education, to achieve the creation of better students daily, to expand their skills and intelligence, the enrich their knowledge and to take advantage of their knowledge in a near future, to teach them to express their ideas and points of views to others without fear, safely and respectfully. Traditional teaching methods do not develop cognitive, social and emotional development in the students, they limit them to passive listening. This is the reason why trainers should be updated to develop cognitive, social and emotional abilities [9].

This results in the search for a method that facilitates the teaching-learning that focuses on students' needs, desires, aspirations, objectives and purposes they want to carry out. The creation of a Curriculum is the role model because it focuses on the overall content to be taught as well as its objectives to be realized within a school or educational system to benefit the student. Though a Curriculum is an important feature in a school program, the development of a
Curriculum needs to be laid out correctly in order for it to function properly. Teacher professional development needs to be concerned with the social aspects of learning, which should be meaningful to students and teachers involved [10].

\subsection{Research Questions}

1. Does having a low English level affect their English Language Learning Process?

2. Which are the negative factors that hinder students' development in the English Language Learning Process?

3. Would a Curriculum redesign be of great support to increment the level of English from students?

4. How effective is the use of a new Curriculum design, and what benefits would it provide to students' learning?

\section{Methodology}

This research followed a stratified sampling method (it is also known as stratifies probability sampling), and the results were recorded in a mixed methodology in order to present a description of the issue, and to give a narrative analysis result rather along with numeric outcomes. The method that was chosen (stratified sampling method) plays an important role because the manner that we intended to obtain the results was going to be laborious, and to ease the arduous process, we decided to opt for this. The Bachelor's Degree in English Language Teaching is constituted of nine semesters. Students who are in first to third semester would not contribute to our research because they do not have a clear understanding of what the Degree is about, and they have not presented an exam that evaluates their language skills, meaning that their output would be unserviceable for this research. This is why it was decided to only question students from fourth to ninth semesters.

\subsection{Participants}

Questionnaires were applied to get specific information about the subject of study, in this case, undergraduates from fourth to ninth semesters. Students answered the difficulties they encountered in their English learning process. Teachers also contributed to the research by filling out a questionnaire that would corroborate students' difficulty with English. This gathered information was compared to medical data in order to obtain a better understating about the proposal of a Curriculum redesign as an element to increase the level of English and avoid the factors that hinder the learning process in ELT students.

\subsection{Instruments}

The research instruments used to collect information were two questionnaires designed for students and for teachers. The first questionnaire is focused on asking students their English level (according to the Common European Framework), and factors that cause problems in their English 
learning process. The second questionnaire is focused on having teachers' opinion that regard students' English level and the difficulties they encounter.

These questionnaires strongly contributed to our research because the objective of both questionnaires was to know students' English level, to know which the main factors are causing problems within the learning process and the difficulties they face. Hence, from that issue, to establish bases on proposing a Curriculum redesign.

\subsection{Procedure}

The population from fourth to ninth semester is approximately one hundred thirty-one (131), though ninth semester forms part of the population that was surveyed; only fourth to eighth semester was sampled differently. The population from fourth to eighth semester is of one hundred twenty (120) students. Interviewing every single student is time-consuming, so half of the population was surveyed (60). This is where the stratified sampling method was used. In order to obtain valuable information, fifty percent was surveyed, which is sixty (60) students out of one hundred twenty (120). Because each semester contains a different student population, it was necessary to use a formula, which would tell us how many students to survey equally, but at the same time, randomly. The data is divided in different categories, under stratus, the semesters are allocated, under students, the number of students per semester, and under students to be surveyed, the total amount to survey per semester. The formula of the stratified sampling method is $\mathrm{fh}=\mathrm{n} / \mathrm{N}=\mathrm{KSh}$.

Table 1. Results of stratified sampling method formula.

\begin{tabular}{lll}
\hline Stratus & Students & Students Surveyed \\
\hline Fourth Semester & 28 & 14 \\
Fifth Semester & 16 & 8 \\
Sixth Semester & 22 & 11 \\
Seventh Semester & 22 & 11 \\
Eighth Semester & 32 & 16 \\
\hline
\end{tabular}

Example:

Nh: 28 students from fourth semester.

Fh:.23 is running variable.

$\mathrm{Nh}: 14$ is the number of students to be surveyed.

Divide $\mathrm{n} / \mathrm{N}=\mathrm{fh}$ (the number of students per semester divided by the entire population, gives the running variable).

$28 / 120=.23$

$16 / 120=.13$

$22 / 120=.18$

$22 / 120=.18$

$32 / 120=.26$

Multiply $\mathrm{Nh} \mathrm{X} \mathrm{fh}=\mathrm{nh}$ (percentage of students that will be surveyed times running variable of each stratus, will give the number of students to interview).

The total number of students to be surveyed is KSh.

$60 X .23=14$

$60 \times .13=8$

$60 \times .18=11$

$60 \times .18=11$
$60 X .26=16$

$60=\mathrm{KSh}$

Since the population of fourth to eighth semester was big, it was important to use a formula, but the most important semester to examine was ninth semester. Ninth semester has a small population, which are elven (11) students. Their opinions are very important because all of the students are in their last semester and have taken every single subject that is in the Degree. Their feedback is essential, and they can even provide with advice on what needs to be modified, for instance, the importance of subjects, the level of English they finished with, whether to add more English hours, so on and so forth. Because these students have practically finished the Degree, every single student from this semester was diagnosed.

\section{Results}

At the time of carrying out this research, research tools were used to fully understand the opinions of students as well as the opinions of teachers. Two questionnaires were designed to extract necessary information from the tested prototypes. The first questionnaire was elaborated to find out students' English level, as well as what thwarts them from learning English, how useful their classes are, and what they would change if possible to do so to upgrade the ongoing situation. The purpose of carrying out this students' questionnaire is to examine the level they have, why they have it and to identify what the causes are.

The results of the first questionnaire are presented in a qualitative manner and some questions are portrayed in a quantitative manner to better understand the percentages. The exemplars who were chosen at random to obtain a general overview are undergraduates from fourth to eight semesters. Students from ninth semester were all interviewed because their opinions were the most important since they have studied the nine semesters in the Bachelor's Degree; the student's population that was surveyed is sixty-eight (this includes students from fourth to ninth semesters). The data collected from thirteen questions gave us a clear understanding of what students think about their English learning process.

The second questionnaire that was applied to teachers consisted on finding out what teachers think of students' English level, and the difficulties they encounter. It is necessary to mention that this questionnaire was applied exclusively to teachers from the Bachelor's Degree that have experience giving English classes.

The results of the second questionnaire are also presented in a qualitative manner. Likewise, some questions are depicted in a quantitative manner to better understand the percentages given by the teachers. The trainers who were chosen have given English classes in the Bachelor's Degree only. The trainers who were surveyed were ten. In addition, a questionnaire with thirteen questions was given to trainers to collect information regarding student's English level and difficulties they face. 
In the questionnaires that were applied to teachers from the Bachelor's Degree in English Language Teaching, the information gathered helped corroborate with the students' questionnaires, which is focused on students' English level and the factors they face that affect their English learning process. Teachers stated that students do not seek for extra information regarding their target language, and this brings consequences which affects their learning. What is more, teachers also said that English should be stipulated in general; this means in subjects, and adding more English hours. To conclude, both teachers and students make learning possible, the teacher gives fifty percent and the student has to give the rest. When this happens, the teaching-learning process is achieved.

\section{Discussion}

During the time of having carried out the research at a Mexican southeastern university, it was observed that students from the Bachelor's Degree in English Language Teaching encounter difficulties when learning English. These undergraduates who face all types of adversities when learning English become affected in the manner that it diminishes their overall English knowledge and their English productivity as well. Hence, students were surveyed to understand what factors they face on a regular basis while studying the career.

In order to avoid and solve most of the problems that students face in the degree, we propose that the Curriculum should be modified. The main reason is because according to our observations and results from the surveys, we can notice that the problems could come from there. By modifying the Curriculum, we believe that there will be better learning opportunities for the scholars. Our proposals that could work as possible solutions to increase the English level in students are: to change Spanish subjects to English, to substitute subjects, to increase pedagogical subjects, to modify the additional languages, and to increase English hours. All the previous proposals would make change in the current Curriculum, so all in all, the proposal of a Curriculum redesign as an element to increase the level of English and avoid the factors that hinder the learning process in ELT students is perhaps the most suitable thing to do.

Something that needs to be addressed in the degree is to change the Spanish subjects to English, except for Spanish Morphosintax. This is the only subject that should not be changed to English because it is fundamental in the Curriculum. As it has been observed, and from the results that were gathered from the questionnaires that were applied to students, it is important to have students exposed to English as much as possible. Students mentioned that they would like to have more contact with the target language, and by having the contents of the subjects in Spanish to English would definitely help the students achieve a higher English level.

It is important to have students exposed to English as much as possible because they are going to be future English teachers, and that is what they should excel in. Having all the subjects in English will increase their abilities in speaking, listening, reading and writing. It must be said that the Bachelor's Degree is meant to have English Language Teachers, and therefore, all of the context that surrounds the Curriculum should be in English.

In addition, students believe that some of the subjects that are in the Curriculum should be substituted permanently by other subjects which will help form an English teacher. Students also believe that there are some subjects in the Curriculum that could be replaced by others and that could have a better impact. There are subjects in the Curriculum that could be taken out and would not affect the role of a future English teacher. Having stated this information, if those existing subjects that do not damage the professional development of an undergraduate were to be replaced by pedagogical subjects, students would grow in their professional development as teachers.

The more involved pupils are with pedagogical subjects, the more their knowledge will expand in this area of expertise. The degree only prepares you theoretically, but it does not prepare you for real life situations like we would like to. This is why we believe that replacing subjects with ones that are related with teaching will prepare undergraduates better theoretically and practically.

Taking additional languages affects students who seek to increment their English level because it becomes time consuming and does not let the students focus only on one language. Students are disoriented from the main language because they have to divide their entire time between two languages, English and the additional language. Though this is not always the case because there are students who have a good English level and are not affected from taking an additional language; they only focus on learning the additional language. This is why the modus in which the additional languages are graded should be revised. The criteria for grading the additional languages could be differently; in this case, accredited or not accredited, they would no longer be compulsory. By doing this, students will be benefited from this because since it will no longer affect them in their final GPA; students can freely focus on learning English without having to worry that they need to pass a subject that will affect them in their language development.

The final proposal is to augment English hours in general per semester, or to have English in the Curriculum from first to ninth semester. The current amounts of English hours that are provided by the Curriculum are not enough to learn the language. If the hours of English are raised, students' English level could be better. Two modifications to the Curriculum are proposed. Firstly, to have students take two English hours daily from first to sixth semester. This would benefit students because in present day, students take English for six semesters, and they only take two hours daily in first and in sixth semester, which means that from second to fifth semester, the number of English hours are reduced. Ideally, to avoid future problems that students may 
face, increasing the quality of activities in the English hours would help.

Secondly, if English is present from first to ninth semester, students would be able to achieve a higher English level. Not only should English be present from first to ninth semester, but two English hours daily would give students a desired English level. This modification could drastically increase their reading, writing, speaking, and listening abilities more than now. It is important to increase the number of English hours because the current Curriculum does not offer enough exposure to the target language in which students are majoring. Students mentioned in the survey that they have certain difficulties. The difficulties that students have could be unencumbered because there would be more opportunities for them to engage with the English language.

To conclude with the proposal, the Curriculum should be redesigned to benefit students, which will benefit the institution as well. The school is going to have graduates who will exceed in English Language Teaching, and this will give a higher reputation to the school which will become prestigious for what it does. The proposals mentioned in this chapter are all important and play an important role in the development of undergraduates who pursue a career in English Language Teaching. To clearly understand the needs of students and what they suggested, depicted next is a comparison of the current Curriculum with the new proposed Curriculum. The table displays first to ninth semester comparisons.

Table 2. Comparison of Current Curriculum and Proposed Curriculum.

\begin{tabular}{|c|c|}
\hline Current Curriculum First Semester & Proposed Curriculum First Semester \\
\hline $\begin{array}{l}\text { Actual society } \\
\text { Learning to learn } \\
\text { English I } \\
\text { Spanish morph syntax } \\
\text { Language didactics } \\
\text { Academic texts writing workshop } \\
\text { Cultural activities } \\
\text { Sports } \\
\text { Nature and society }\end{array}$ & $\begin{array}{l}\text { Teaching strategies } \\
\text { Neurolinguistics } \\
\text { English I } \\
\text { Spanish morph syntax } \\
\text { Language didactics } \\
\text { Academic texts writing workshop } \\
\text { Introduction to Linguistics }\end{array}$ \\
\hline Second Semester & Second Semester \\
\hline $\begin{array}{l}\text { Origin of knowledge } \\
\text { English II } \\
\text { English for academic purposes: Reading } \\
\text { Foreign language I (German, French or Italian) } \\
\text { Introduction to Linguistics } \\
\text { Trends in Education } \\
\text { Cultural activities } \\
\text { Sports } \\
\text { Sustainable development }\end{array}$ & $\begin{array}{l}\text { English II } \\
\text { English for academic purposes: Reading } \\
\text { Foreign language I (German, French or Italian)* } \\
\text { Phonetics and Phonology } \\
\text { Trends in Education } \\
\text { English morph syntax } \\
\text { Developments in Language Teaching Methodology }\end{array}$ \\
\hline
\end{tabular}

\begin{tabular}{ll}
\hline Third Semester & Third Semester \\
\hline Technologies in Education & Spelling \\
English III & English III \\
English for academic purposes: Speaking & English for academic purposes: Speaking \\
Foreign language II (German, French or Italian) & Foreign language II (German, French or Italian)* \\
Phonetics and Phonology & Phonetics and Phonology II \\
Developments in Language Teaching Methodology & English morph syntax II \\
Observation of the Teaching Practice & Observation of the Teaching Practice \\
Cultural activities & \\
Sports & \\
\hline
\end{tabular}

\begin{tabular}{ll}
\hline Fourth Semester & Fourth Semester \\
\hline English IV & English IV \\
English for academic purposes: writing & English for academic purposes: writing \\
Foreign language III (German, French or Italian) & Foreign language III (German, French or Italian)* \\
English Linguistics & English Linguistics \\
Grammar Teaching Didactics & Grammar Teaching Didactics \\
Reading Didactics & Reading Didactics \\
Cultural activities & Translation techniques \\
Sports & \\
Educational Technology & \\
\hline
\end{tabular}




\begin{tabular}{ll}
\hline Fifth Semester & Fifth Semester \\
\hline English V & English V \\
Development of the English Language & Development of the English Language \\
Foreign language IV (German, French or Italian) & Foreign language IV (German, French or Italian)* \\
Writing didactics & Writing didactics \\
Speaking didactics & Speaking didactics \\
Teaching Children & Teaching Children \\
Tutoring & Teaching Teenagers and Adults \\
\hline & \\
\hline Sixth Semester & Sixth Semester \\
\hline English VI & English VI \\
Foreign language V (German, French or Italian) & Foreign language IV (German, French or Italian)* \\
Sociolinguistics & Sociolinguistics \\
Learning Assessment & Learning Assessment \\
Teaching Practice & Teaching Practice \\
Introduction to Research & Introduction to Research \\
Tourism & Material Design \\
\hline & \\
\hline Seventh Semester & Seventh Semester \\
\hline English Language Literature & English Language Literature \\
Foreign language VI (German, French or Italian) & Foreign language VI (German, French or Italian)* \\
Discourse Analysis & Discourse Analysis \\
Design of Programs for Teaching English as a Foreign Language & Design of Programs for Teaching English as a Foreign Language \\
Teaching Practice Workshop & Teaching Practice Workshop \\
Educational Research & Educational Research \\
Material Design & \\
\hline
\end{tabular}

\begin{tabular}{ll}
\hline Eighth Semester & Eighth Semester \\
\hline Social service & English VIII \\
& Social service \\
\hline & \\
\hline Ninth Semester & Ninth Semester \\
\hline Art and culture & English IX \\
Psychological Aspects of Language Learning & British culture \\
Dissertation Seminar & American culture \\
& Dissertation Seminar \\
\hline
\end{tabular}

*The additional language is not a compulsory subject within the new Curriculum; meaning that it does not affect the students' credits or the Grade Point Average. It is evaluated as ACCREDITED or NOT ACCREDITED.

\section{Conclusion}

To summarize, this research shows that the majority of students who are currently studying the Bachelor's Degree in English Language Teaching have a low-intermediate level, which is not enough for their future professional development in English Language Teaching. Thus, finding a solution to improve this situation was proposed. Also, in this research, some of the factors that impede the learning process were mentioned and explored.

The general objective of this research was to identify the factors that affect or impede that students achieve a competitive English level, and then establish the necessary bases for a Curriculum redesign. The proposal of a Curriculum redesign would be the ideal solution for the problems that were identified through the questionnaires that were applied to students. The solutions would be more English hours, subjects in English, and subjects oriented to their vocation which will help with their academic development in becoming English teachers.

It is important to highlight one of the main key points in this research, the new Curriculum proposed by students. This new Curriculum would help improve students' learning and would also target students' English level.

The findings from the research helped us accomplish the general objective. Some suggestions were taken into account according to the results that were drawn from the questionnaires which were applied to students from the Bachelor's Degree. These suggestions led to the proposal of a new Curriculum. Furthermore, students' feedback showed that the Mission and Vision of the school can be improved by taking into account their opinions.

There are always ways of improving, and there are also different approaches, strategies in achieving certain objectives. In this research, one of the ways of improving students' English level, and enhancing the learning process was via questionnaires, which assisted in the research as an essential tool. We as teachers need to be updated not only to understand our surroundings, but also to satisfy our students' needs. It is difficult to be a teacher, because one never stops learning, and there is not a zenith to teaching and learning, it is the latter statement which is sheer essence. 


\section{References}

[1] Truscott, A. (2016). Teacher development for bilingual education in Colombia. Towards teacher empowerment. Estudios sobre Educación, 31, 15-35.

[2] Ahmed, S. (2015). Attitudes towards English Language Learning among EFL learners at UMSKAL. Journal of Education and Practice, 6(18). 6-16.

[3] Jiménez, O., Batista, J., Bagarotti, Y., Rodríguez, M., \& Espinosa, T. (2015). La estrategia curricular de idioma inglés, a través de la disciplina teoría y metodología social. Pedagogía Universitaria, XX(4), 49-76.

[4] Haidara, Y. (2016). Psychological factors affecting English speaking performance for the English learner in Indonesia. Universal Journal of Education and Research, 4(7), 15011505 .

[5] Alrabai, F. (2016). Factors underlying low achievement of Saudi EFL learners. International Journal of English Linguistics, 6(3), 21-37.

[6] Gu, M., \& Benson, P. (2015). The formation of English teachers' identities: a cross-cultural investigation. Language Teaching Research, 19(2), 187-206.

[7] Peercy, M., Martin-Beltrán, M., Silverman, R., \& Daniel, S. (2015) Curricular design and implementation as a site of teacher expertise and learning. Teachers and Teaching, 21(7), 867-893. DOI: 10.1080/13540602.2014.995486

[8] Banegas, D. (2016). Exploring perceptions of curriculum change in initial English Language Teacher Education: a case in Argentina. Estudios sobre Educación, 31, 75-95.

[9] Yilorm, Y. \& Acosta, H. (2016). Neoliberalismo y proceso de enseñanza-aprendizaje de la lengua inglesa en Chile: una mirada dialéctica al estado del arte en sectores vulnerables. Revista Cubana de Educación Superior, 3, 125-136.

[10] Voogt, J., Laferrière, T., Breuleux, A., Itow, R., Hickey, D., \& McKenney, S. (2015). Collaborative design as a form of professional development. Instructional Science, 43(2), 259282. 